International Journal of Automotive and Mechanical Engineering ISSN: 2229-8649 (Print); ISSN: 2180-1606 (Online)

Volume 15, Issue 2 pp. 5161-5177 June 2018

(C) Universiti Malaysia Pahang, Malaysia

DOI: https://doi.org/10.15282/ijame.15.2.2018.2.0399

\title{
The Evaluation of k- $\varepsilon$ and k- $\omega$ Turbulence Models in Modelling Flows and Performance of S-shaped Diffuser
}

\author{
M. A. Abd Halim, N. A. R. Nik Mohd", M. N. Mohd Nasir and M. N. Dahalan \\ Aeronautical Laboratory, Department of Aeronautics, Automotive and Ocean \\ Engineering, Faculty of Mechanical Engineering, \\ Universiti Teknologi Malaysia, 81310 Skudai Johor, Malaysia \\ Email: ridhwan@utm.my
}

\begin{abstract}
Diffusing S-shaped ducts are critical components in modern vehicle, primarily employed in directing the airflow to the engine. It links the air box and the engine in a very restricted place. The air flow through an S-duct is complex in nature, which perhaps includes boundary layer separation, secondary flow, and total pressure loss effects that influences the engine performance. In this work, the flow and performance of S-shaped duct was predicted and analysed using computational fluid dynamics. The main objective is to evaluate the performance of the realizable $k-\varepsilon$ and $k-\omega$ SST models qualitatively and quantitatively in modelling flow of a highly bend duct where a high stress distorted flow may have developed in proximity the duct wall leading to stall. CFD computations were performed for the flow entering the diffuser at Reynolds number of 80,000 cases. The results obtained suggested that the $k-\omega$ SST model reasonably predicts the flow characteristics qualitatively and quantitatively. The realizable $k-\varepsilon$ turbulence model however poorly captures the actual magnitudes of the calculated flow features. The growth of the stream-wise velocity profile was calculated at three stream-wise stations and point out a smooth down the interior profile of the divergent section. An extreme flow distortion and a shift of the region of flow with the highest velocity were developed toward the outer wall of the first bend of the diffuser. A significant pressure recovery potential with no flow separation arise over the diffuser tube range was predicted well by the simulations.
\end{abstract}

Keywords: CFD; performance; S-shaped diffuser; conical; validation.

\section{INTRODUCTION}

Diffusing S-shaped ducts can be found in various combustion processes with air breathing system [1-3]. The curve of the S-shaped duct is often used to link the air box and the engine in a very restricted place. Study of flow characteristics within the curved duct configuration has been of fundamental interest to researchers [4-9] in the area of fluid dynamics for centuries. Turbulent flows in passages with gradually varying crosssectional area and bends are presented in a large variety of applications particularly in aircraft and ground vehicle, used for converting kinetic energy into pressure energy. When the airflow is travelling over a curved surface, an adverse pressure gradient may occur within the boundary layer and the flow will begin to detach from the surface leading to flow separation, stall and further influences the engine performance. 
Practical approach using computational fluid dynamics (CFD) for intake aerodynamic design to improve aerodynamic performance of the S-duct was introduced by Goldsmith and Seddon [10]. Studies such as the flow in planar symmetrical diffusers and predicting the formation of symmetric [11] or asymmetric [12] separated flow regions depending on the divergence angle and Reynolds number has been applied using the Reynolds Averaged Navier-Stokes (RANS) approach. Gerolymos et al. [13] adopted Reynolds stress model to analyse the flow field structure of a dual S-duct. According to Lee et al. [14], the characteristics of Allison 250 S-shaped diffuser outperformed its variant giving that over its entire length has a cross-sectional area expansion extending. Computational fluid dynamics had been a developed heading science and innovation movement by being taken a cost compelling, deciding arrangements for complex project challenges, consolidation of progressed. The continuously increasing computational capabilities have allowed the in-depth study of transitional and turbulent flows in curved and toroidal pipes by means of large-eddy (LES) and direct numerical simulations (DNS). Boersma and Nieuwstadt [6] performed LES, while Hüttl and Friedrich [15]; Giannakopoulos et al. [16] employed DNS to study the influence of curvature on the mean and fluctuating flow. Research conducted by Di Piazza and Ciofalo [17] resolves the turbulent flow in helically coiled pipes with heat transfer using DNS. By comparing their DNS results, the authors found that the $\kappa-\omega$ SST and RSM- $\omega$ performed reasonably well in computing the friction and heat-transfer coefficient of the flow even at high curvature.

Lee et al. [18] studied the three-dimensional numerical and experimental analysis of the airflow inside an Allison 250 conical diffuser tube using three different turbulence models, which are the $k-\varepsilon, k-\omega$ and SST models. The research reveals that the different turbulent models has striking variations in both the required computational time and the prediction capability. A detailed computational investigation of flows in diffusing S-shaped ducts has been carried out by Menzies [19] proved that SST results match experiment the best when compared with S-A and k- $\omega$ models. Only that, one of the main problems of turbulence closures is the transition of the free stream from laminar to turbulent over the intake cowl region inside the intake flows. Gan and Zhang [20] used $k$ - $\omega$ SST turbulence model to design an S-duct. Lee et al. [21] study on flow characteristics of the inlet shape for the s-duct using $k$ - $\omega$ SST to simulate the flow under adverse pressure gradient better. Thus, it is indicated that the result of Shear Stress transport (SST) model was more reliable than the S-A, k- $\varepsilon$, and $k-\omega$ models.

Diffuser geometry has a strong relationship with its performance [22-24]. The optimum effectiveness of the S-shaped diffuser was reported can be achieved with the total divergence angle of approximately $7^{\circ}$ and the ratio of the diffuser length to the exit width not exceeding $25^{\circ}$. However, in determining the pressure recovery, the divergence angles and the area ratio are insignificant variables. Reneau et al. [23] practice the design and mapping of two-dimensional diffusers. The result found out that the approach covers only the pressure recovery between the inlet and the outlet of the diffusers whilst the flow-structure within the diffusers is excluded. In a finding by Sparrow et al. [25] found that flow separation happened for a diverging angle of $5^{\circ}$ for inlet Reynolds numbers less than approximately 2000. The dissimilarity of these findings proven that flow separation at a divergence angle of $7^{\circ}$ does not necessary to happen. Flow separation happened at $10^{\circ}$ and $30^{\circ}$ at diverging angles for all investigated Reynolds numbers. Lower Reynolds numbers produces larger stream wise length of the separation zones. Gibson [26] reports the pressure loss in the diverging pipes and passage. The research concludes that in a circular pipe with uniformly 
diverging boundaries, the total loss of head attains its minimum value with an angle equal to about $5^{\circ} 30^{\prime}$. On the other hand, the loss of head in a pipe of square section is greater at the least $20 \%$.

The flow in diffusing S-ducts is a complex study [27] due to the effects that starts from the intake port to the engine face plane. The flow of air is expected to move through the duct efficiently in a similar motion to the second bend. However, a significant low energy flow occurs on the outside wall relative to the second bend of the tube which does not driven back circumferentially and causes strong pressure driven stream-wise vortices.

In this work, flow dynamics in a curved tube was calculated numerically with the aims at evaluating the detailed flow fields and the pressure recovery using two different two-equation turbulence models. The ability of the turbulence models used in treating a highly sheared and distorted flow field will be evaluated to develop understanding in terms of limitations offered by the turbulent model. The numerical analysis was done using the grid-based, cell-centred finite volume CFD solver ANSYS Fluent. Due to the over-predicted result of the Standard $k-\varepsilon$ conducted by Lee et al. [18], the advanced Realizable $k$ - $\varepsilon$ was also assessed against the Menter's [28] $k$ - $\omega$ shear stress transport (SST) model and experimental work of Lee et al. [18].

\section{GEOMETRICAL PARAMETERS}

In the present work, flow dynamics in an S-shaped diffuser have been examined. The diffuser used is similar to the A250 diffuser conducted by Lee et al. [18]. The diffuser consists of $155.2 \mathrm{~mm}$ conical sections that have smooth transitions into a continuous diameter S-duct of length $270.8 \mathrm{~mm}$ as showed in Figure 1. The inlet and outlet diameter is $46.83 \mathrm{~mm}$ and $65.11 \mathrm{~mm}$, respectively. Geometry was drawn into half due to symmetrical shape with the origin axis is at the centre of station 1. Figure 1 and Figure 2 (in $\mathrm{mm}$ ), shows the dimensions of the diffuser tube. The figures include the inlet and outlet diameters with offsets between them and the lengths of the conical and S-shaped sections.

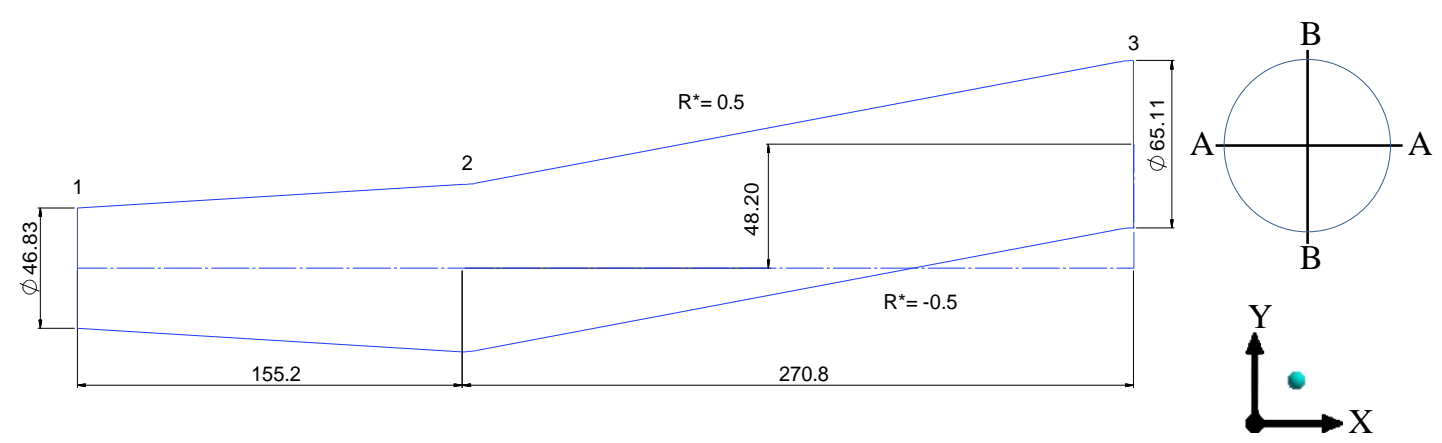

Figure 1. A250 diffuser tube and pressure measurement stations (reproduced from Lee et al. [18])

Figure 1 shows the adjoin of the combustion chamber and turbine at the top edge of the diffuser tube from station 2 to station 3. That surface is referred to as $\mathrm{R}^{*}=0.5$ which is the inner wall of the first bend. Consequently, the bottom edge will be referred to as at $\mathrm{R}^{*}=-0.5$ which is the outer wall of the first bend. Consistently with the experimental setup [18] shown in Figure 2, a $1.5 \mathrm{~m}$ entry length upstream the diffuser 
tube was used to allow the flow to fully develop before entering the inlet of the Sshaped area. The downstream of the diffuser tube was extended for $1 \mathrm{~m}$ used to place the boundary condition at an adequate distance away from the outlet of S-shaped area.

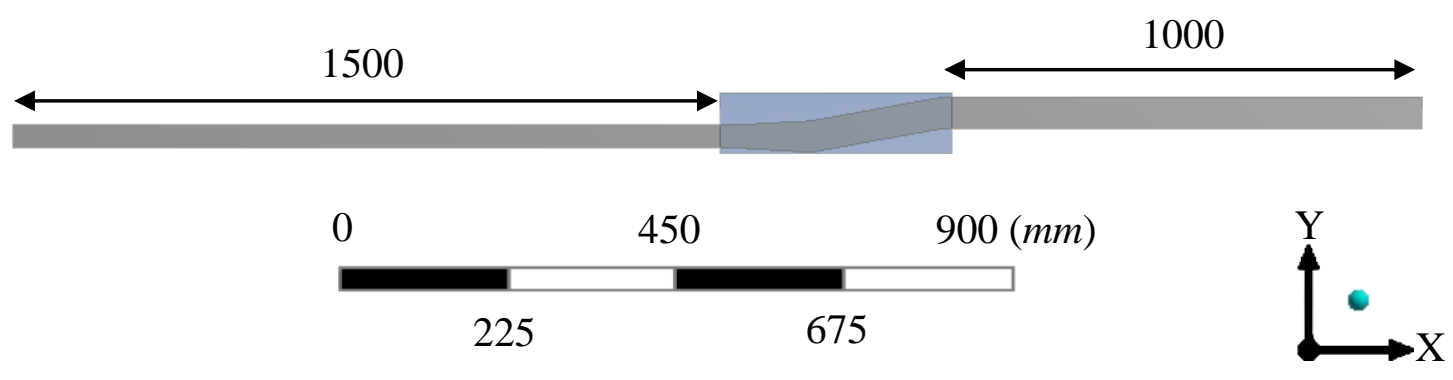

Figure 2. Extension of A250 diffuser tube.

The simulation follows the experimental condition [18] which requires a Reynolds number of 80,000 and a mass flow-rate of $0.055 \mathrm{~kg} / \mathrm{s}$. Consequently, terms $\mathrm{Z}^{*}$ and $\mathrm{R}^{*}$ are the dimensionless number by the local diffuser tube diameter with respect to radial coordinates $\mathrm{z}$ (AA direction) and $\mathrm{r}$ (BB direction) respectively. The axial coordinate normalised by the total diffuser tube length is termed as $\mathrm{X}^{*}$, and the streamwise component of velocity vector normalised by the local bulk velocity is termed as $\mathrm{U}^{*}$.

\section{NUMERICAL MODELLING}

\section{Governing Equations}

A commercially available CFD solver, ANSYS Fluent 11 has been used throughout this work. The governing equations [29] for the mean flow in reduced form for steady incompressible flows is given in Eq. (1) and (2).

$\frac{\partial \rho}{\partial t}+\frac{\partial}{\partial x_{i}}\left(\rho u_{i}\right)=0$

$\frac{\partial}{\partial t}\left(\rho u_{i}\right)+\frac{\partial}{\partial x_{j}}\left(\rho u_{i} u_{j}\right)=\frac{\partial \rho}{\partial x_{i}}+\frac{\partial}{\partial x_{j}}\left[u_{e f f}\left(\frac{\partial u_{i}}{\partial x_{j}}+\frac{\partial u_{j}}{\partial x_{j}}-\frac{2}{3} \delta_{i j} \frac{\partial u_{1}}{\partial x_{l}}\right)\right]+\frac{\partial}{\partial x_{j}}\left(-\rho \overline{u_{i}^{\prime} u_{j}^{\prime}}\right)$

where $u$ is the velocity vector written in Einstein notation, $\rho$ is the fluid density. These equations have the same general form as the instantaneous Navier-Stokes equations, with the velocities and other solution variables representing the time-averaged values. Additional terms now appear that represents the effects of turbulence. These Reynolds stresses, $-\rho \overline{u_{i}^{\prime} u_{j}^{\prime}}$ must be modelled in order to close the momentum equation.

In this work, two-equation turbulence models are considered. Two-equation turbulence model is chosen due to its adequate accuracy in modelling turbulent flows at reliable cost over the higher-order turbulence models. The first turbulent model considered is the Realizable $\mathrm{k}-\varepsilon$ model which is based on the following transport Eq. (3) and (4). 


$$
\begin{aligned}
& \frac{\partial}{\partial \mathrm{t}}(\rho \mathrm{k})+\frac{\partial}{\partial \mathrm{x}_{\mathrm{j}}}\left(\rho \mathrm{ku}_{\mathrm{j}}\right)=\frac{\partial}{\partial \mathrm{x}_{\mathrm{j}}}\left[\left(\mu+\frac{\mathrm{u}_{\mathrm{t}}}{\sigma_{\mathrm{k}}}\right) \frac{\partial \mathrm{k}}{\partial \mathrm{x}_{\mathrm{j}}}\right]+\mathrm{P}_{\mathrm{k}}+\mathrm{P}_{\mathrm{b}}-\rho \varepsilon-\mathrm{Y}_{\mathrm{M}}+\mathrm{S}_{\mathrm{K}} \\
& \frac{\partial}{\partial \mathrm{t}}(\rho \varepsilon)+\frac{\partial}{\partial \mathrm{x}_{\mathrm{j}}}\left(\rho \varepsilon \mathrm{u}_{\mathrm{j}}\right)=\frac{\partial}{\partial \mathrm{x}_{\mathrm{j}}}\left[\left(\mu+\frac{\mathrm{u}_{\mathrm{t}}}{\sigma_{\varepsilon}}\right) \frac{\partial \varepsilon}{\partial \mathrm{x}_{\mathrm{j}}}\right]+\rho \mathrm{C}_{1} \mathrm{~S} \varepsilon-\rho \mathrm{C}_{2} \frac{\varepsilon^{2}}{\mathrm{k}+\sqrt{v \varepsilon}}+\mathrm{C}_{1 \varepsilon} \frac{\varepsilon}{\mathrm{k}} \mathrm{C}_{3 \varepsilon} \mathrm{P}_{\mathrm{b}}+\mathrm{S}_{\varepsilon}
\end{aligned}
$$

where,

$$
\begin{aligned}
& C_{1}=\max \left[0.43, \frac{\eta}{\eta+5}\right] \\
& \eta=S \frac{k}{\varepsilon} \\
& S=\sqrt{2 S_{i j} S_{i j}}
\end{aligned}
$$

In this work, steady state is considered. Thus, unsteady terms in Eq. (3) and (4) can be dropped. The Realizable k- $\varepsilon$ model has been developed to satisfy certain mathematical constraints on the normal stresses and consistent with the physics of turbulent flows [29]. It represents an improvement over the standard k- $\varepsilon$ model [30] where it contains a new formulation for the turbulent viscosity and a new transport equation for the dissipation rate, $\varepsilon$. The dissipation rate is derived from an exact equation for the transport of the mean-square vorticity fluctuation. It is reported to have a good performance in capturing flows with rotation, strong adverse pressure gradients, recirculation, mixing, channel and boundary layer flows around planar and round jets flows that may occur in the S-shaped duct under certain flow condition. The second turbulence closure considered is the $\mathrm{k}-\omega$ model with shear stress transport (SST) $[28,29]$.

$$
\begin{aligned}
& \frac{\partial}{\partial \mathrm{t}}(\rho \mathrm{k})+\frac{\partial}{\partial \mathrm{x}_{\mathrm{j}}}\left(\rho \mathrm{ku}_{\mathrm{j}}\right)=\frac{\partial}{\partial \mathrm{x}_{\mathrm{j}}}\left[\left(\mu+\sigma_{k} \mu_{t}\right) \frac{\partial \mathrm{k}}{\partial \mathrm{x}_{\mathrm{j}}}\right]+\rho \mathrm{P}-\beta^{*} \rho \omega \mathrm{k} \\
& \frac{\partial}{\partial \mathrm{t}}(\rho \omega)+\frac{\partial}{\partial \mathrm{x}_{\mathrm{j}}}\left(\rho \omega \mathrm{u}_{\mathrm{j}}\right)=\frac{\partial}{\partial \mathrm{x}_{\mathrm{j}}}\left[\left(\mu+\sigma_{\omega} \mu_{\mathrm{t}}\right) \frac{\partial \omega}{\partial \mathrm{x}_{\mathrm{j}}}\right]+\frac{\gamma}{v_{\mathrm{t}}} \mathrm{P}-\beta \rho \omega^{2}+2\left(1-\mathrm{F}_{1}\right) \frac{\rho \sigma_{\omega 2}}{\omega} \frac{\partial \mathrm{k}}{\partial \mathrm{x}_{\mathrm{j}}} \frac{\partial \omega}{\partial \mathrm{x}_{\mathrm{j}}}
\end{aligned}
$$

Unsteady terms in Eq. (5) and (6) is dropped due to the steady state condition. The terms $F_{1}$ for the $k-\varepsilon$ model is neglected as is it goes far from the wall surface whilst for the k- $\omega$ model converts to one is it goes near the boundary layer. The model is a combination of the k- $\omega$ turbulence model and k- $\varepsilon$ turbulence model such that the k- $\omega$ plays a role in the inner region of the boundary layer and it switches to the k- $\varepsilon$ in the far from the wall surface flow. The calculation of the distance from the wall is obtained by the solution of a Poisson equation.

The pressure-velocity correlation coupled between velocity and pressure using SIMPLE [31]. Spatial discretization was performed with least squares cell-based gradients and second-order accurate scheme of pressure. To reduce the discontinuity, oscillation and spurious in the prediction of momentum, turbulent kinetic energy and specific dissipation rate in the region with a high gradient, the third-order accurate Monotonic Upwind Scheme for Conservative scheme of Laws (MUSCL) by Van Leer [32] was used. The assumption of an isotropic turbulence field used in this turbulence 
model was applied to the current application. The sum of normalized residual for each conservation equation was less than or equal to $10^{-5}$ assumes that the solution is converged.

\section{Discretization of Elements}

The physical geometry of the S-shaped diffuser was discretized with tetrahedron dominated elements as shown in Figure 3. Unstructured grid generation on complicated S-Duct geometries was considered reliable, efficient, and quick [33]. To treat the flow in the viscous sub layer region accurately, the mesh in the boundary layer was constructed with 25 layers of hexahedral elements with the $\mathrm{y}^{+} \leq 1\left(\Delta \mathrm{y}=2.724 \times 10^{-5} \mathrm{~m}\right)$. $\mathrm{y}^{+}$is defined as the wall distance non-dimensionalised by the friction. Mesh expansion in the boundary layer is developed to follow the exponential distribution as shown in Figure 4.

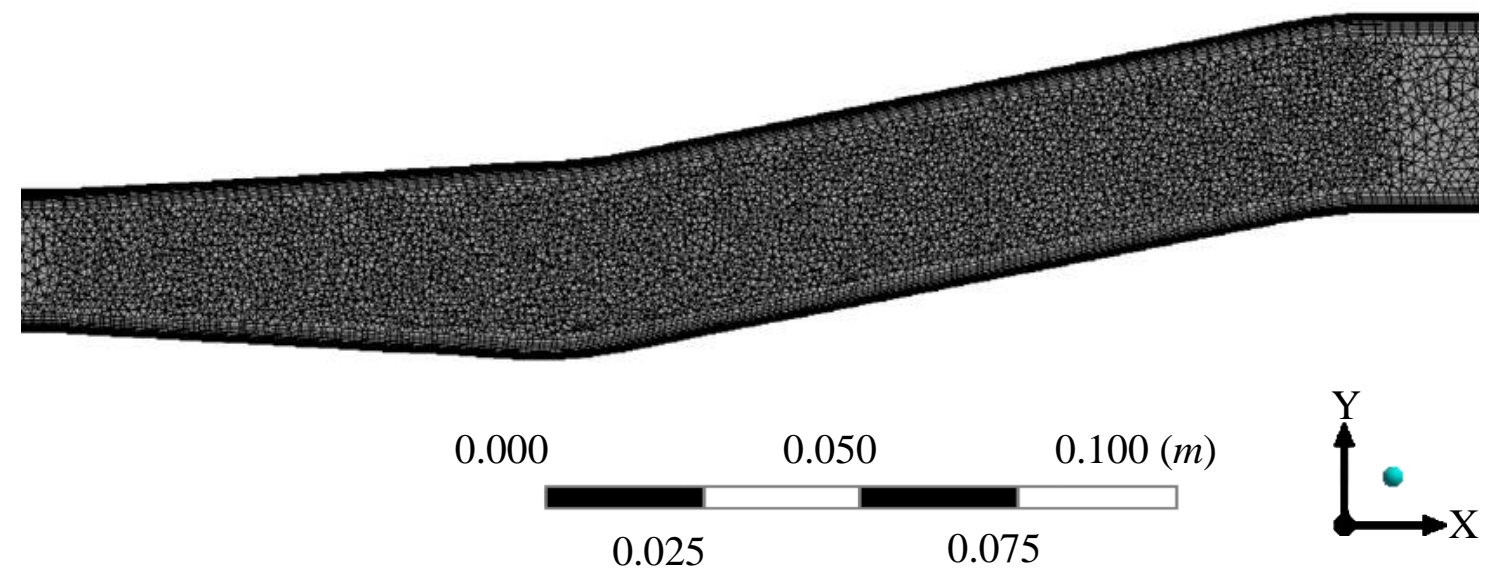

Figure 3. Global mesh topology.

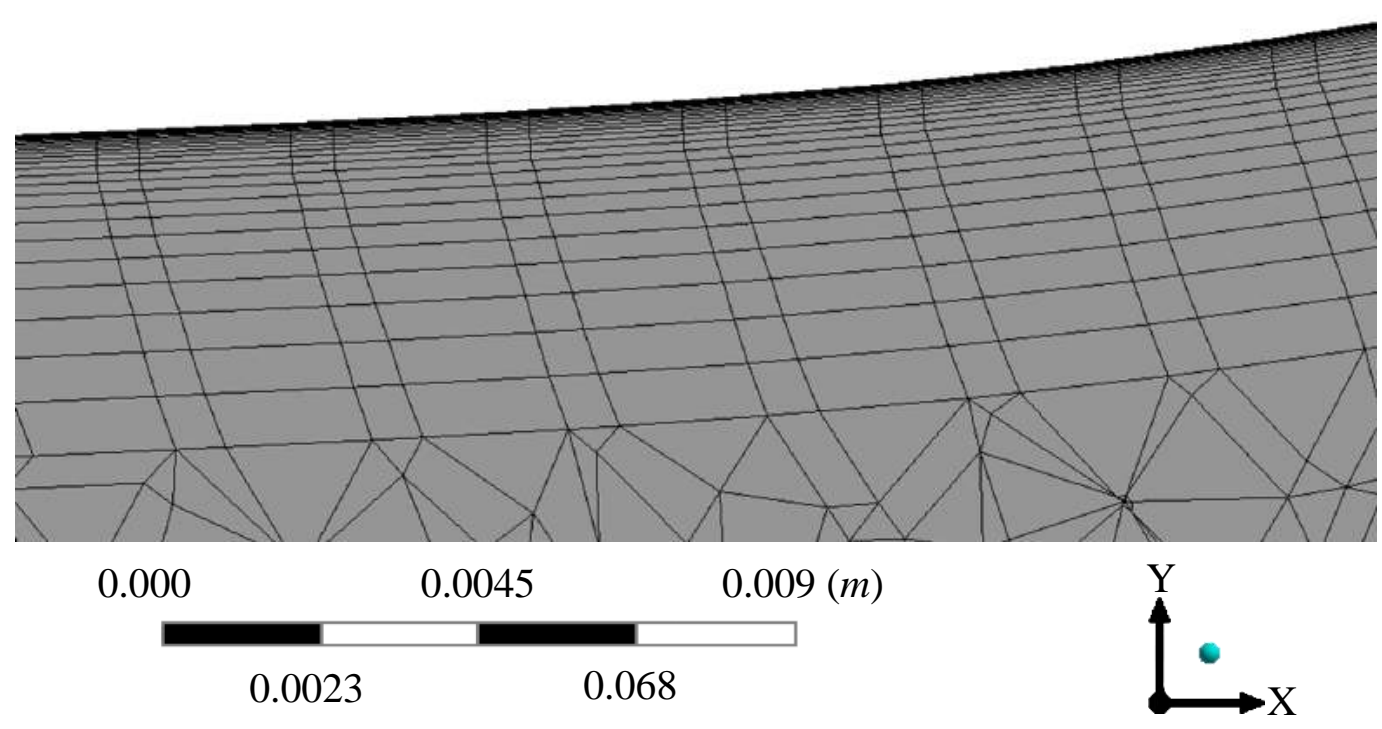

Figure 4. Close views of the inflation layer. 


\section{Mesh Independence Study}

To provide a solution that is independence of mesh, at least for accurately capturing the pressure and velocity distribution inside the diffuser, a mesh independence study was performed [34]. The changes in the average velocity due to the change in the mesh resolution taken at station 3 is shown in Figure 5. The mesh independence study shows at least 1.03 million mesh elements are needed for the solution to be an independence of mesh. Thus, mesh with 1.53 million elements are considered throughout this work.

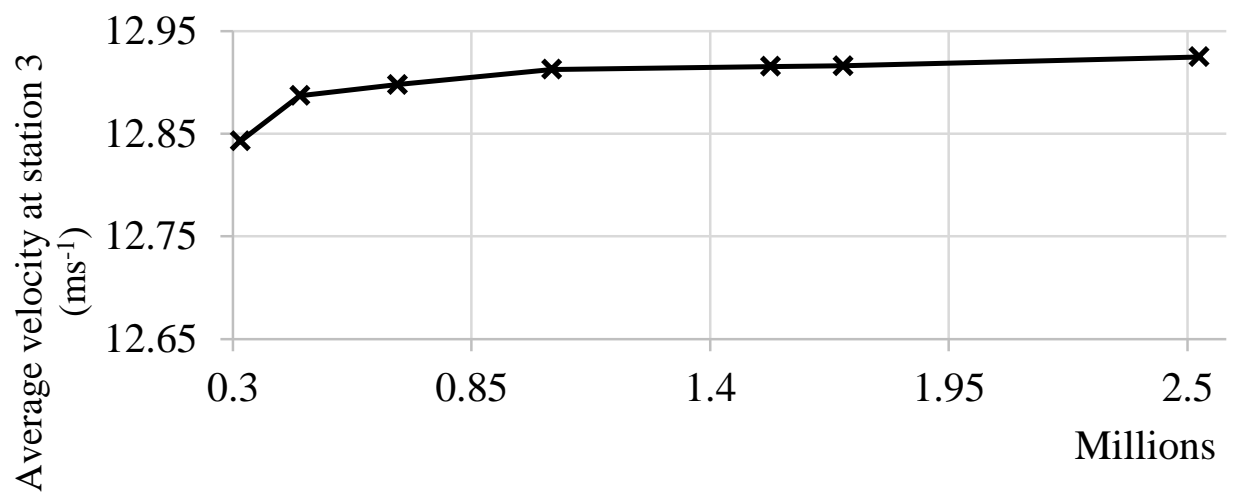

Number of elements

Figure 5. Mesh independence study

\section{Boundary Conditions}

CFD domain and the boundary conditions used are shown in Figure 6. For the upstream boundary condition, velocity-inlet boundary condition was used as the inlet condition. Whereas the downstream boundary of the duct, the pressure-outlet setting at atmospheric pressure condition was used. Since only half of the geometry was used in the simulation, the symmetry boundary condition was applied to the symmetry plane (green). Air was used as fluid media, which was assumed to be steady and incompressible. The near-wall cell thickness was calculated to satisfy the logarithmic law of the wall boundary. Other fluid properties were taken as constants where, the air density, $\rho=1.225 \mathrm{~kg} / \mathrm{m}^{3}$ and dynamic viscosity, $\mu=1.7894 \mathrm{e}-5 \mathrm{~kg} / \mathrm{m} . \mathrm{s}$. Table 1 shows the summarization of the CFD parameters and its values. 


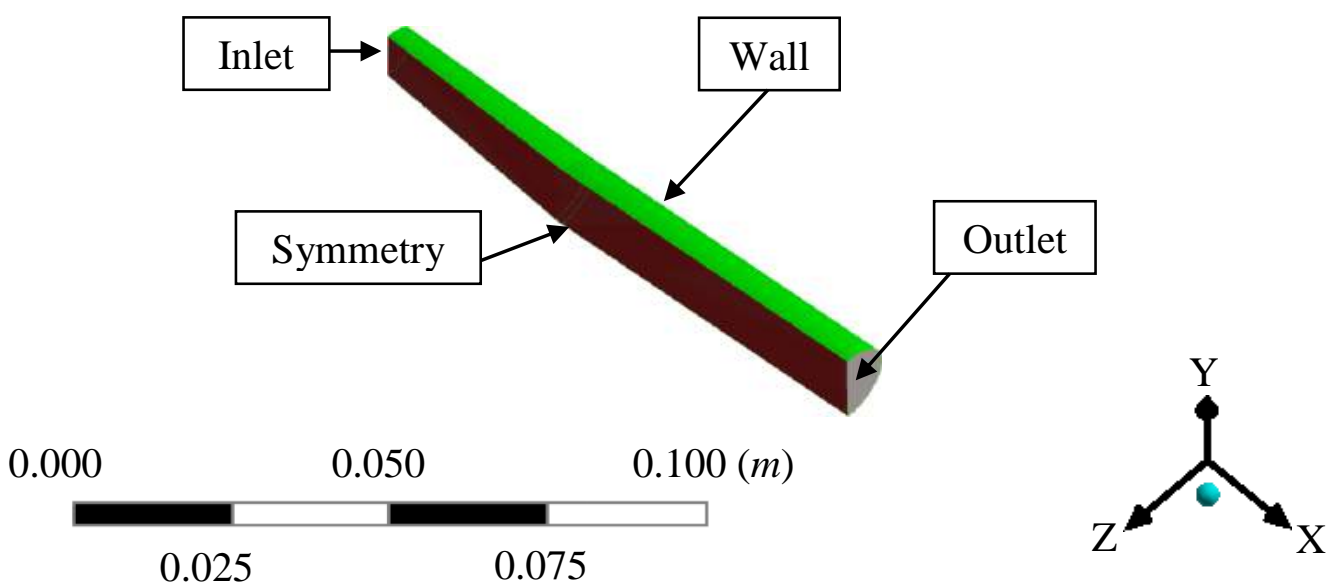

Figure 6. Boundary conditions for A250 diffuser tube.

Table 1. Summary of CFD solver set up.

\begin{tabular}{ll}
\hline Parameters & Values \\
\hline Reynolds number & 80000 \\
Inlet turbulence intensity of & $5 \%$ \\
Solution method & Steady state \\
Solution algorithm & SIMPLE \\
Turbulence model & Realizable k- $\varepsilon$ and k- $\omega$ SST model \\
Maximum residual tolerance & 0.00001 \\
Resolution scheme & Second-order, Third-order MUSCL \\
$\mathrm{y}^{+}$value & 1 \\
\hline
\end{tabular}

\section{RESULTS AND DISCUSSION}

\section{Comparison of Different Turbulence Models with Experimental Data}

Comparisons of the stream-wise velocity profile in the A250 S-shaped diffuser calculated using CFD is presented. Figures 7-9 show the stream-wise velocity profile taken at three different stations viewed from AA line whereas Figures 10-12 are viewed from the $\mathrm{BB}$ line. The stream-wise velocity profile suggests that the velocity is symmetry when viewed from the AA line. At station 1, the calculated velocity profile shows that the air entering the inlet plane of the S-shaped diffuser with a fully developed flow. At this stage, the k- $\omega$ SST turbulent model provide an excellent prediction comparable to experimental measurement. The Realizable k- $\varepsilon$ model, however, shows that the model over predicts the velocity profile at the centre line of the tube.

At station $2\left(\mathrm{R}^{*}=0.5\right)$ and station $3\left(\mathrm{R}^{*}=-0.5\right)$, both turbulence models used show good prediction of the velocity profile near the wall. Further extend away from the wall at $\mathrm{R}^{*}=-0.5$, the $\mathrm{k}-\omega \mathrm{SST}$ model shows that the local velocity developed its strength from the wall surface up to $\mathrm{U}^{*}>1$ at $\mathrm{R}^{*}=0.4$ similar to the experiment but under predict the velocity towards the centreline. The Realizable k- $\varepsilon$, however, poorly predict the radial velocity in the inner region of the free sheer flow. The erroneous 
prediction is due to Realizable $\mathrm{k}-\varepsilon$ over predicts the radial velocity when approaching region $\mathrm{r} \geq 70 \mathrm{~mm}$ [35].

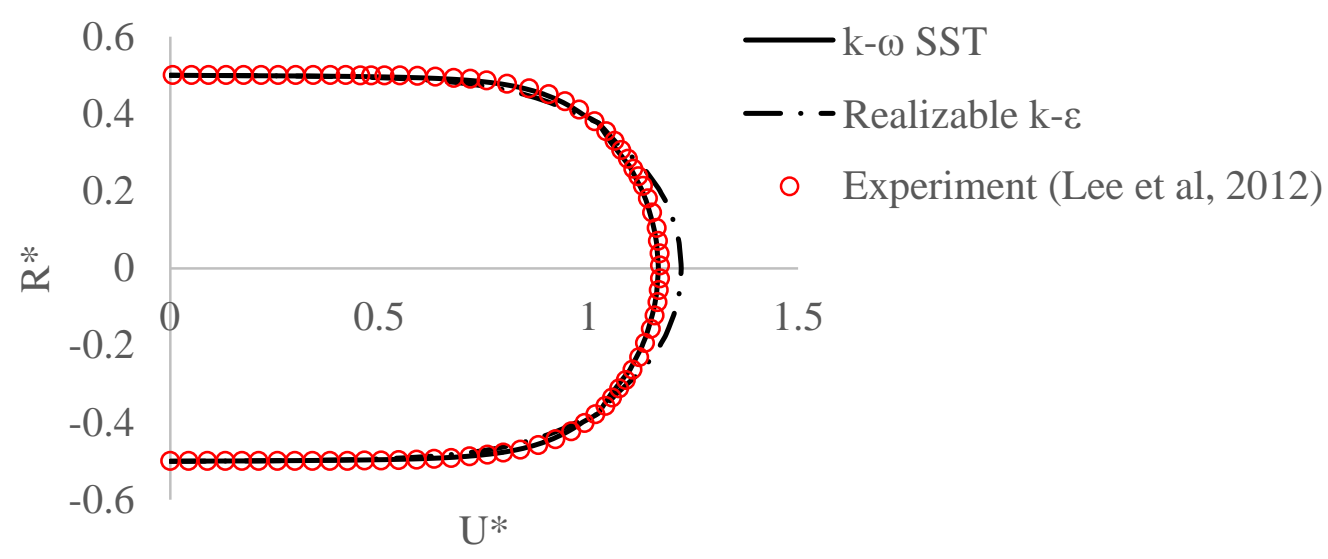

Figure 7. Comparison of stream-wise velocity profile at Station 1 (AA line).

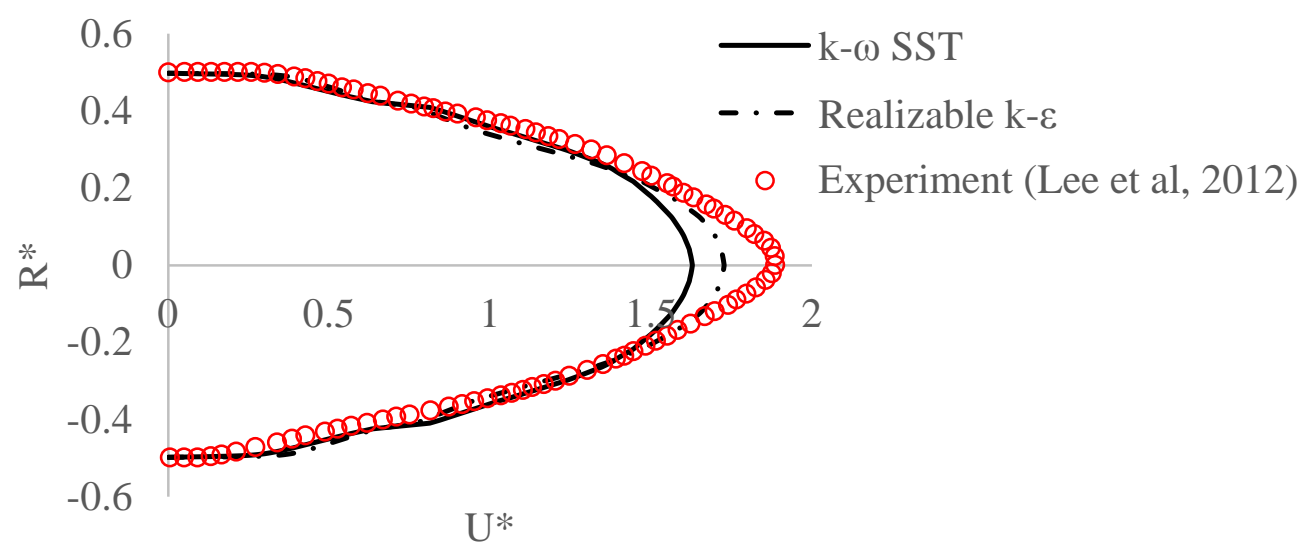

Figure 8. Comparison of stream-wise velocity profile at Station 2 (AA line).

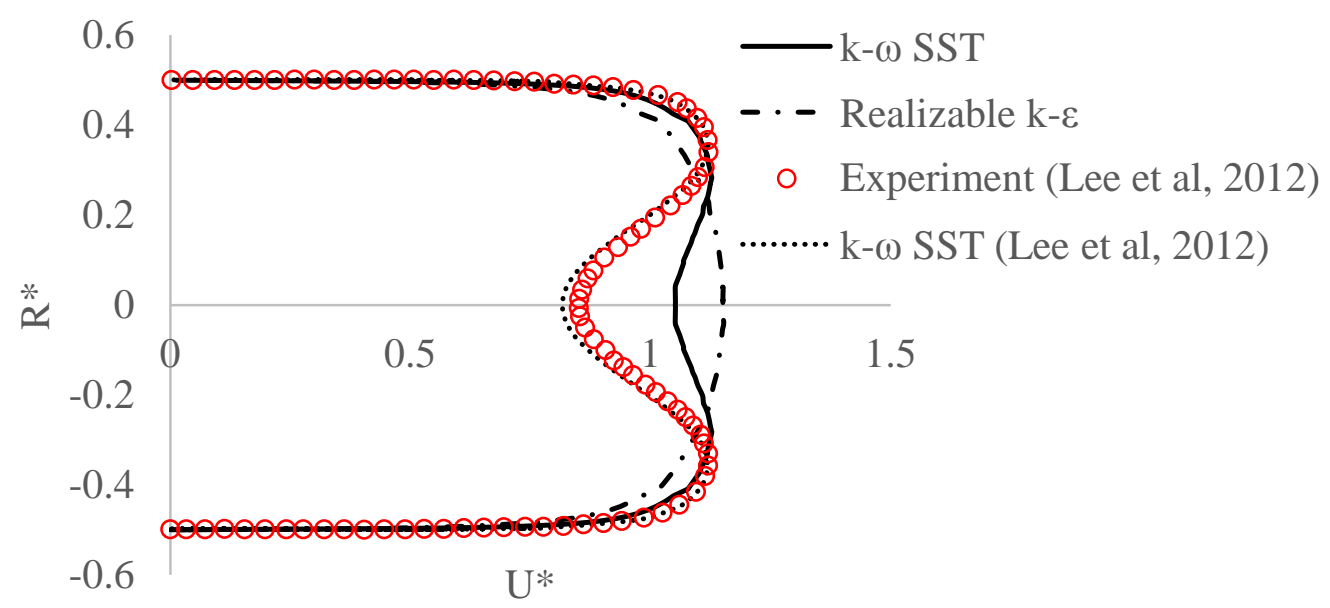

Figure 9. Comparison of stream-wise velocity profile at Station 3 (AA line). 


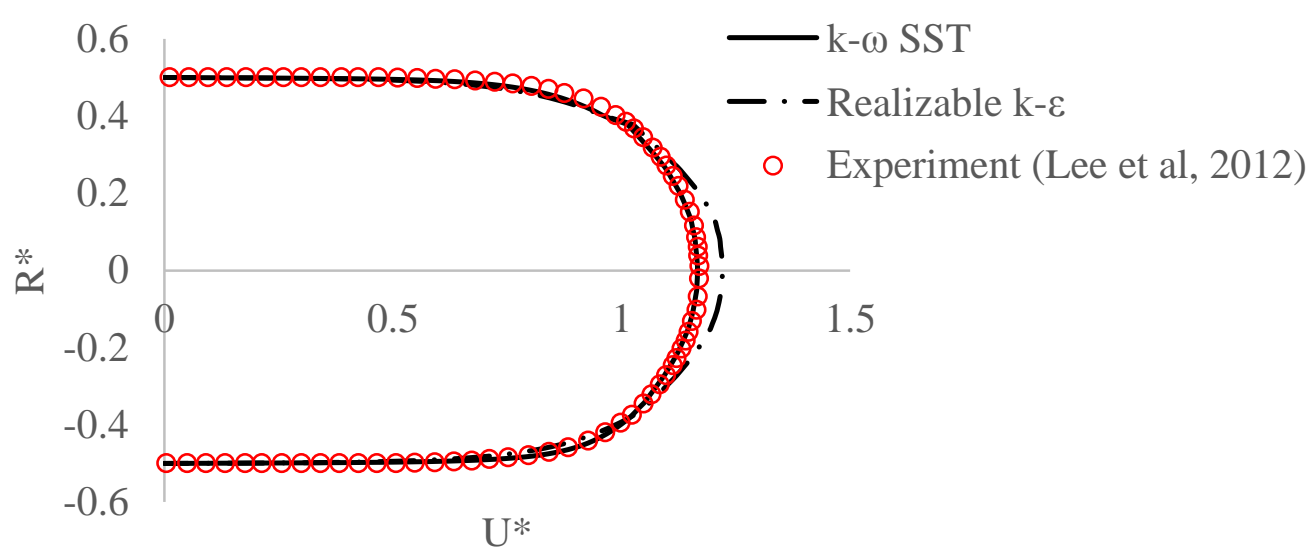

Figure 10. Comparison of stream-wise velocity profile at Station 1 (BB line).

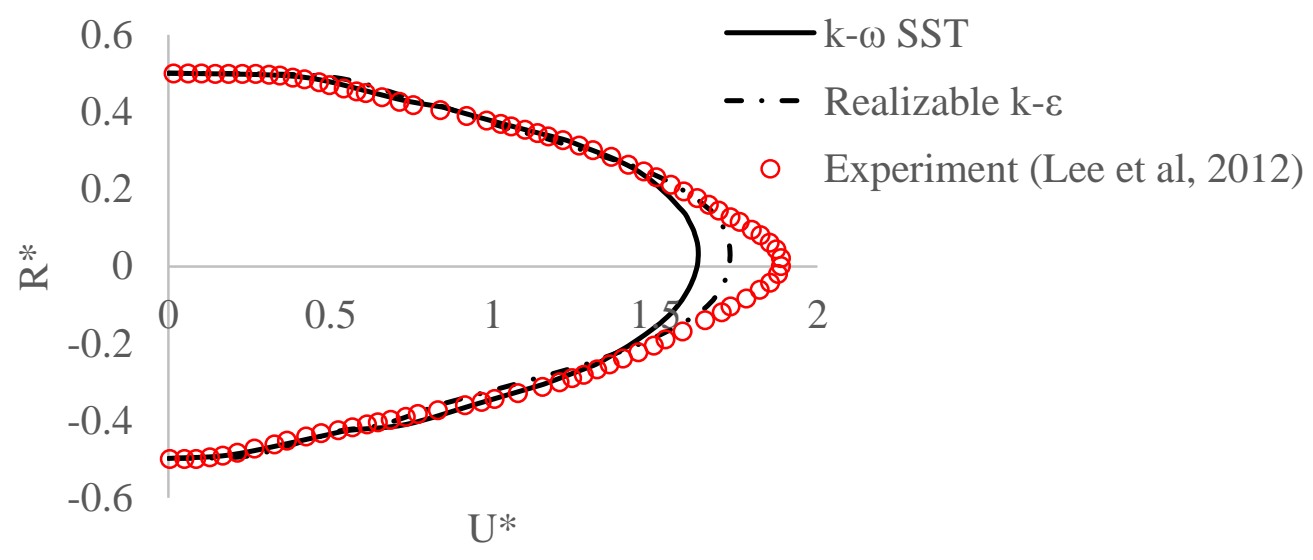

Figure 11. Comparison of stream-wise velocity profile at Station 2 (BB line)

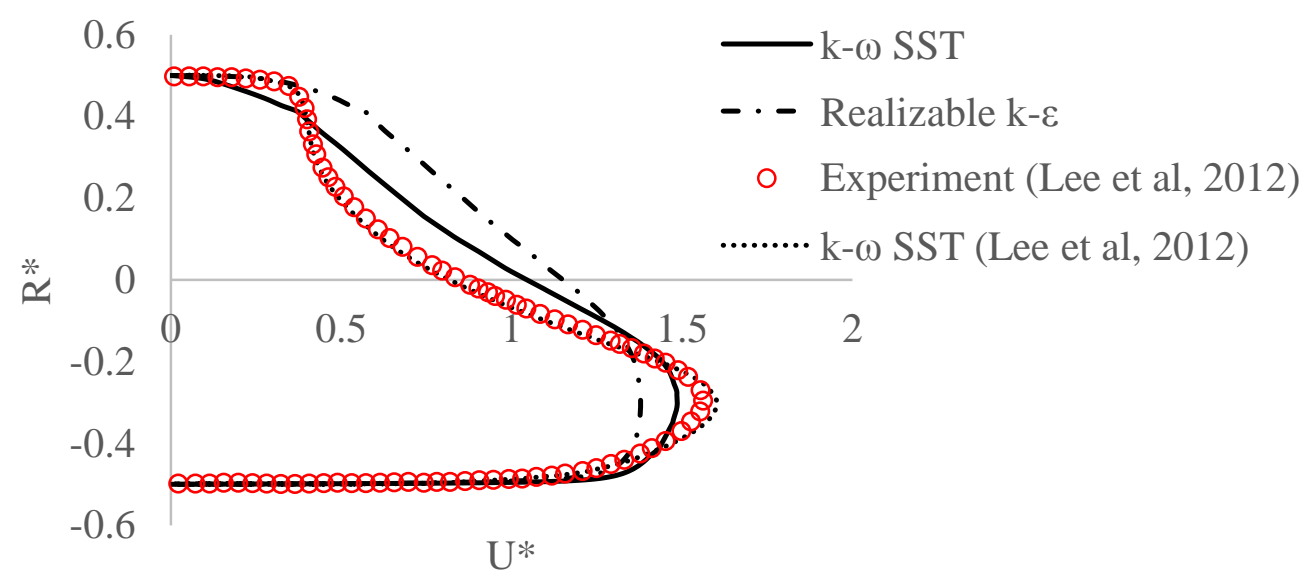

Figure 12. Comparison of stream-wise velocity profile at Station 3 (BB line)

From the present work, the distribution of the non-dimensional stream-wise velocity at Station 1 (in Figure 7 and Figure 10) shows very good agreement as reported in the experiment. At station 2 (in Figure 8 and Figure 11), as the air leaving the 
divergence section of the duct towards a constant cross-sectional area but inclined by $45^{\circ}$ from horizontal axis, the air speed is accelerating. The boundary layer is expanding. Within this section, it can be seen that the Realizable k- $\varepsilon$ outperformed k- $\omega$ SST model as the Realizable $\mathrm{k}-\varepsilon$ model proves to capture flows with strong adverse pressure gradients. The stream-wise velocity profile starts to flatten by way of the highest velocity is forced toward free shear flow. Simulation by Lee et al. [18] showed a very good agreement with experiment for station 3. This is due to the used of higher order accurate algorithm for pressure-velocity coupling used in the work of Lee et al. [18]. In Figure 9 and Figure 12 obviously reveal that the Realizable k- $\varepsilon$ model is not suitable for this case though it needs a greater computation time than the k- $\omega$ SST model. The Realizable k- $\varepsilon$ model fails significantly by over-predicting the shear stress at the inner wall of the first bend at station 3. On the other hand, the k- $\omega$ SST model predicts the same trends as the experiment in terms of qualitative, but the quantitative results are way-out. It can be concluded that these two turbulent model's performances are mainly affected by the highly boundary layer controlled.

\section{Development of the Stream-Wise Velocity Profile}

Figure 13 depicts the calculation of the k- $\omega$ SST model in development of stream-wise velocity profile developed along the diffuser tube under condition of 80,000 Reynolds number and $5 \%$ of inlet turbulence intensity. The velocity profile in AA direction from Figure 13 (b) is almost symmetrical and steady smooth downstream about the centreline. It is noted that the velocity profile flow becoming lower approaching the wall region. Along the BB line in Figure 13 (a), the symmetrical profile at the inlet of the diffuser tube gets progressively contorted towards the wall at $\mathrm{R}^{*}=-0.5$, while the stream near the wall at $\mathrm{R}^{*}=0.5$ is decelerated.

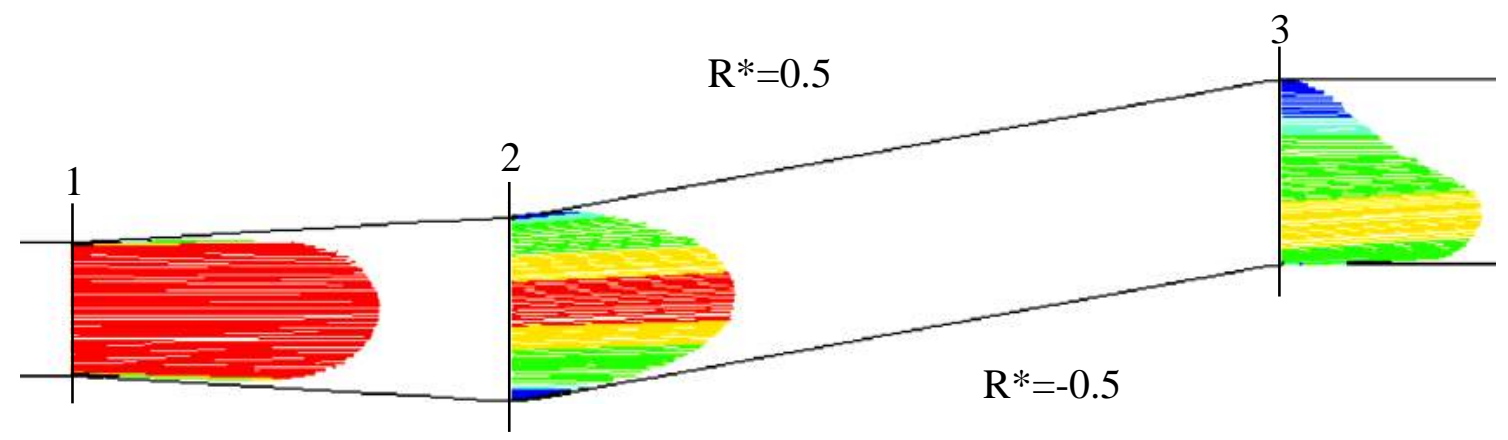

(a) AA line 


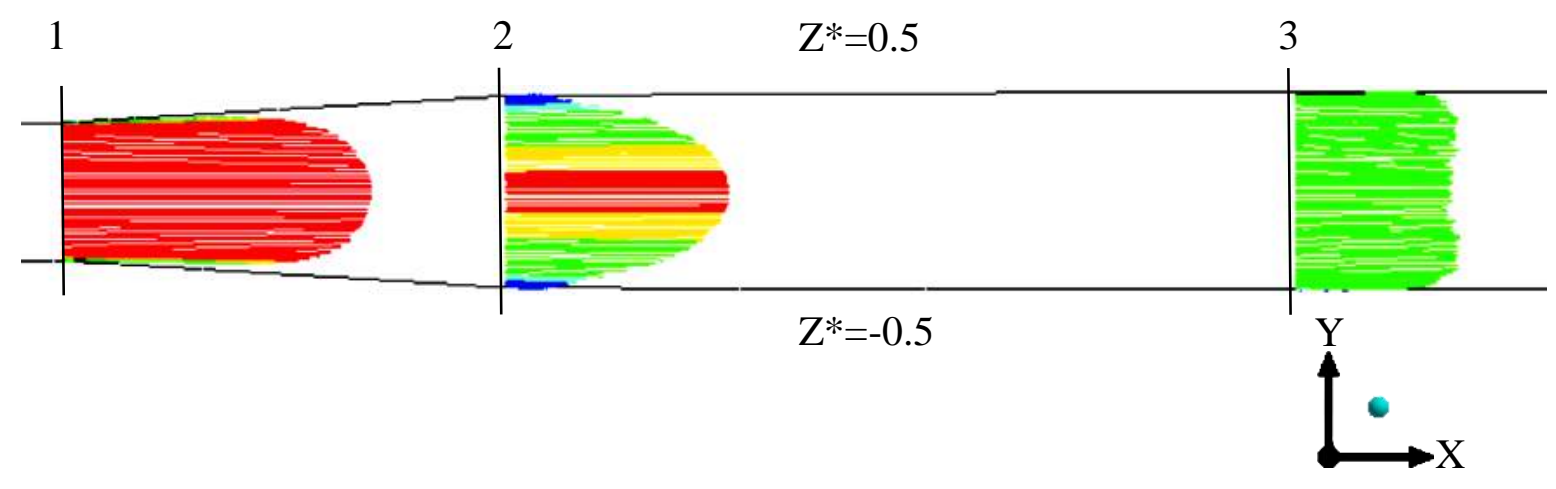

(b) BB line

Figure 13. Development of the stream-wise velocity profile from (a) side and; (b) top view.

Figure 14 shows the contour of the stream-wise velocity in the plane of the cross-section of the diffuser tube at 3 different stations predicted using k- $\omega$ SST turbulence model. The results show that the k- $\omega$ SST predicts a symmetrically streamwise circulated at the entrance of the diffuser tube $(X=0 \mathrm{~m})$ with the highest velocity occur in the core region (Figure 14a). At the end of the conical portion $(\mathrm{X}=0.1552 \mathrm{~m}$ ) in BB-axis, the highest velocity starts (Figure 14b) to shift vertically from the center region and towards the outer wall of the first bend. The shift phenomena becomes significantly increase in the downstream of the tube. In the horizontal direction (AA), the profile is again symmetrical throughout the tube, same as in Figure 13b. The work of Lee and $\mathrm{Yu}$ [36] also summarizes the consistent observations. 


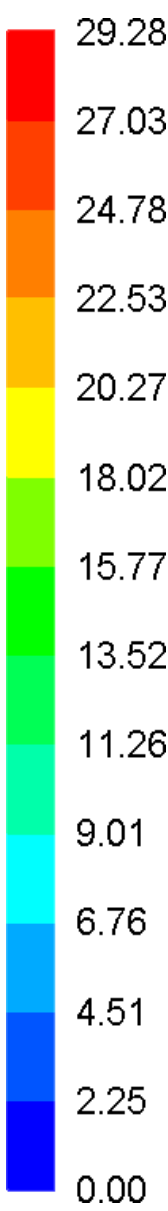

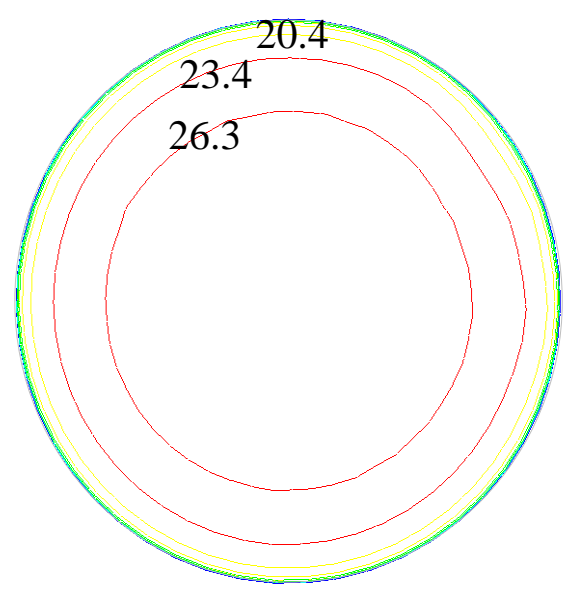

(a)

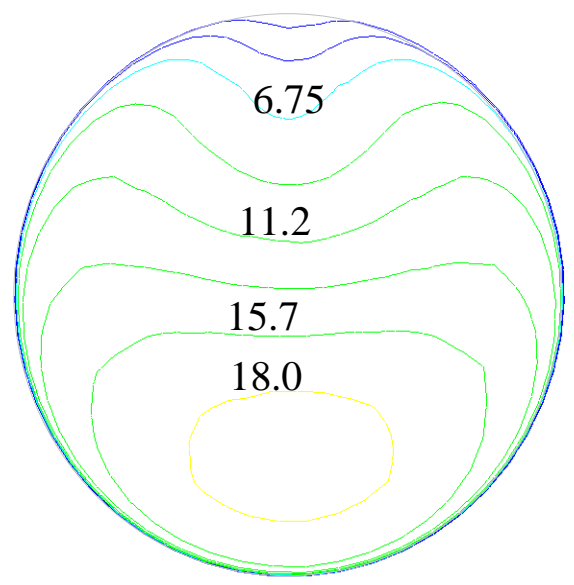

(c)

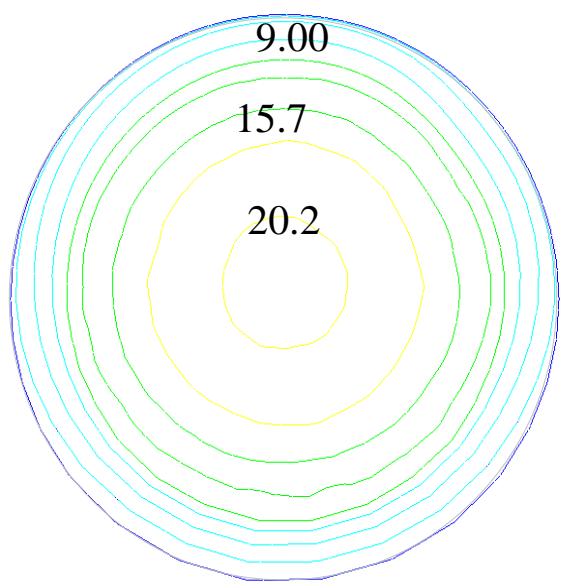

(b)

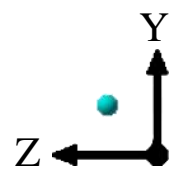

Figure 14. Velocity contours $\left(m s^{-1}\right)$ visualised at (a) $\mathrm{X}=0 \mathrm{~m}$; (b) $\mathrm{X}=0.1552 \mathrm{~m}$; (c) $\mathrm{X}=$ $0.426 m$

The dynamics of the secondary flow calculated using k- $\omega$ SST and visualised at three different stations along the diffuser tube are shown in Figure 15. The figures show that at the entrance, the stream-wise velocity is directed outward of the diffuser tube (Figure 15a). In Figure 15b, it is observed that the secondary flow push towards top edge wall of the first bend with a greater intensity towards the end of the conical section of the tube remaining to the curvature of the diffuser tube. This shows that the mean flow near the wall of the first bend has started to accelerate and producing very high velocity to the free shear wall of the first bend. A pair of increasing counter-rotating vortices strength is found to occur at $\mathrm{X}=0.426 \mathrm{~m}$ (Figure 15c) and swiftly reverts throughout the downstream. 


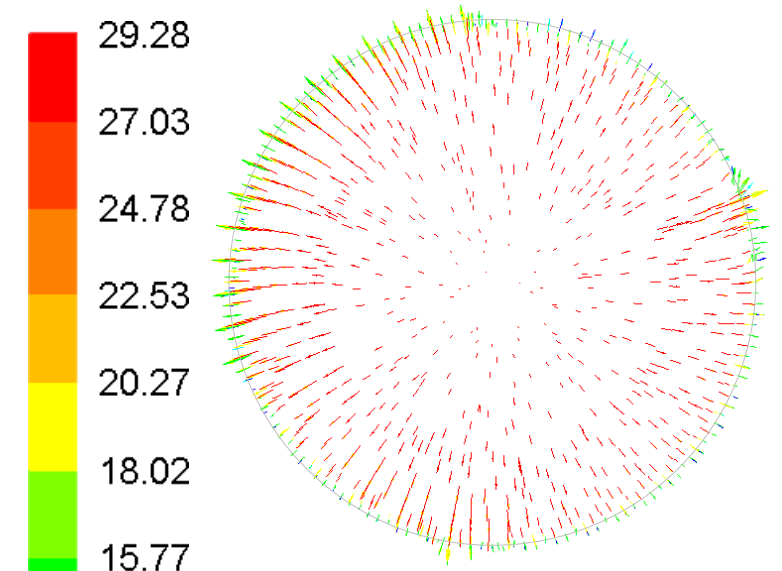

(a)

13.52

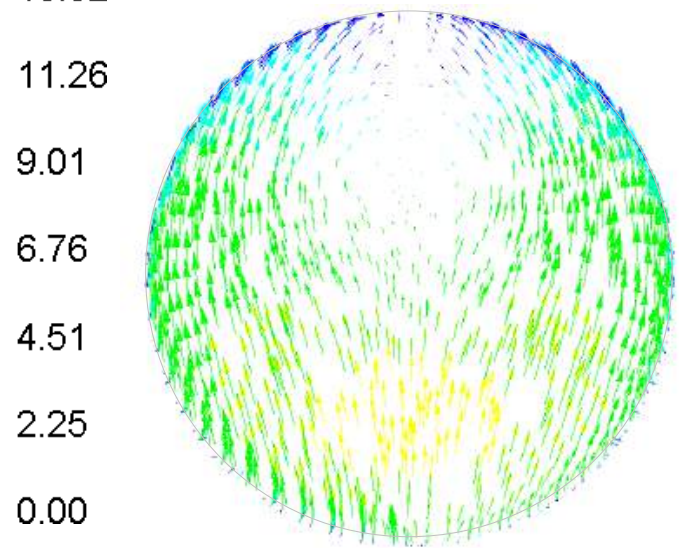

(c)

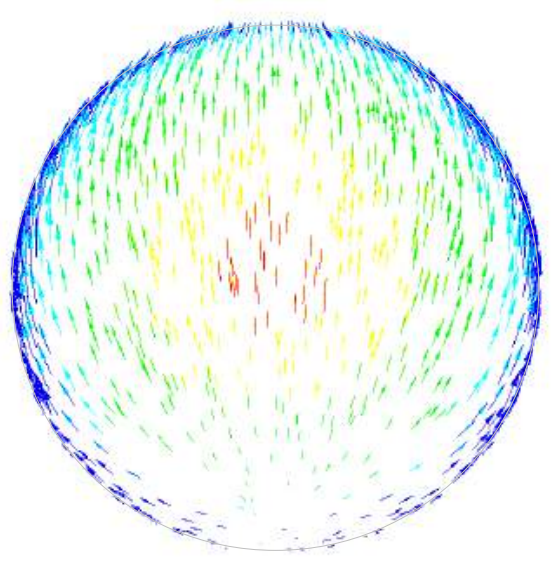

(b)

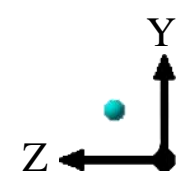

Figure 15 . Velocity vectors coloured by velocity magnitude $\left(\mathrm{ms}^{-1}\right)$ at (a) $\mathrm{X}=0 \mathrm{~m}$;

(b) $\mathrm{X}=0.1552 \mathrm{~m}$ and; (c) $\mathrm{X}=0.426 \mathrm{~m}$.

\section{Effect of Skin Friction Coefficient, $C_{f}$}

Figures 16 and 17 show the comparison of the calculated skin friction coefficient, $C_{f}$ against the CFD data of Lee et al. [18]. $C_{f}$ starts to decrease rapidly at the wall at R* $=$ 0.5 in the conical section of the diffuser tube. At the convex bend, the $C_{f}$ briefly and decrease gradually until $X^{*}=0.8$ where the boundary layer starts to separate from the surface. At the second bend, the friction coefficient starts to increase again. Near the outer wall of the first bend (in Figure 17), the friction coefficient decreases as the flow passage expands. At low Reynolds number at the concave bend, the $C_{f}$ value is near zero then sharply increase after the section until the convex bend, at which the friction coefficients drop abruptly. 


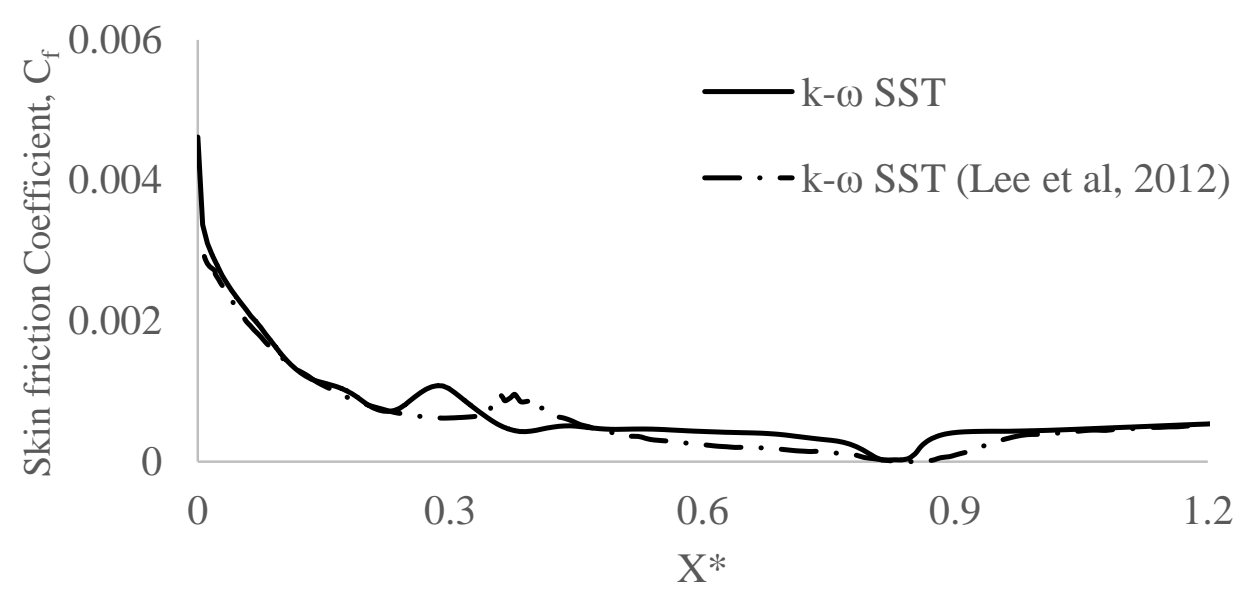

Figure 16. Skin friction coefficients on wall at $\mathrm{R}^{*}=0.5$

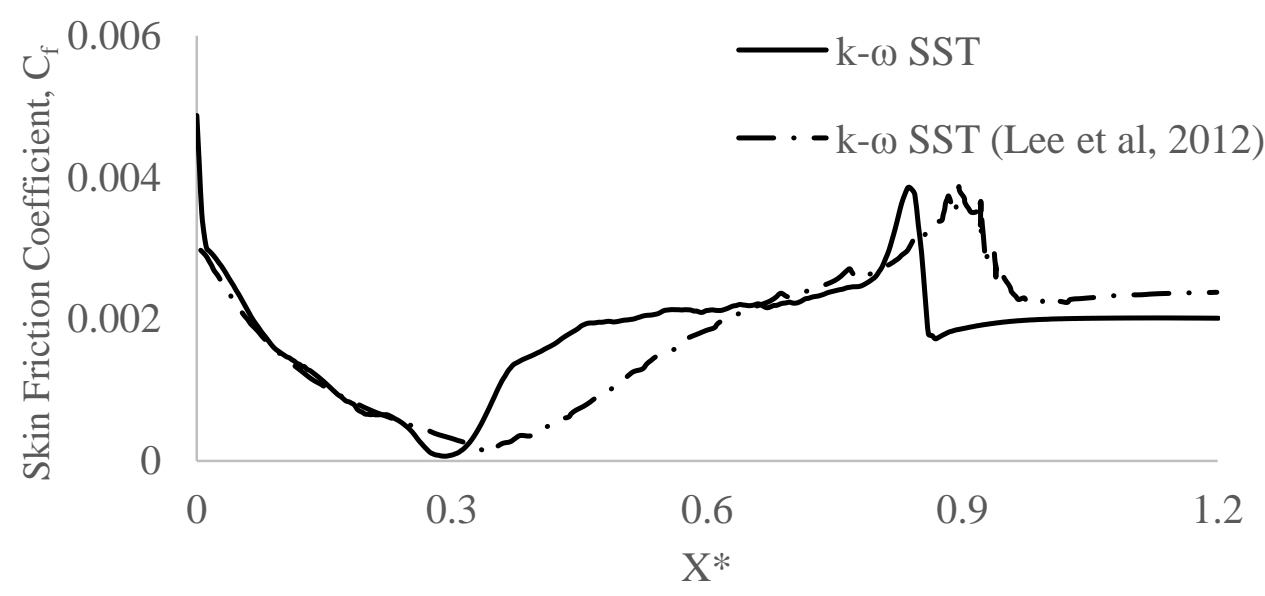

Figure 17. Skin friction coefficients on wall at $R^{*}=-0.5$

\section{Pressure Drop across the Centre Line of the Tube}

As depicted in Figure 18, the calculated pressure drops across the constant diameter tube from the inlet to the entry of the diffuser tube $(\mathrm{X}=-0.0204 \mathrm{~m})$ is approximately 244.293. The pressure intensively increases from the entry of the diffuser tube to the first bend $(\mathrm{X}=0.1552 \mathrm{~m})$ about $201.393 \mathrm{~Pa}$. Pressure continues increases smoothly but fluctuates throughout the first bend to the second bend $(X=0.426 \mathrm{~m})$ until reaches 25.866 $\mathrm{Pa}$. Cross through the constant diameter tube from the exit of the second bend to the exit of the tube, pressure increases until $27.617 \mathrm{~Pa}$ and then gradually drop to $0.0254 \mathrm{~Pa}$. Overall, the pressure drops from $30.974 \mathrm{~Pa}$ at the inlet to $0.0254 \mathrm{~Pa}$ at the outlet. 


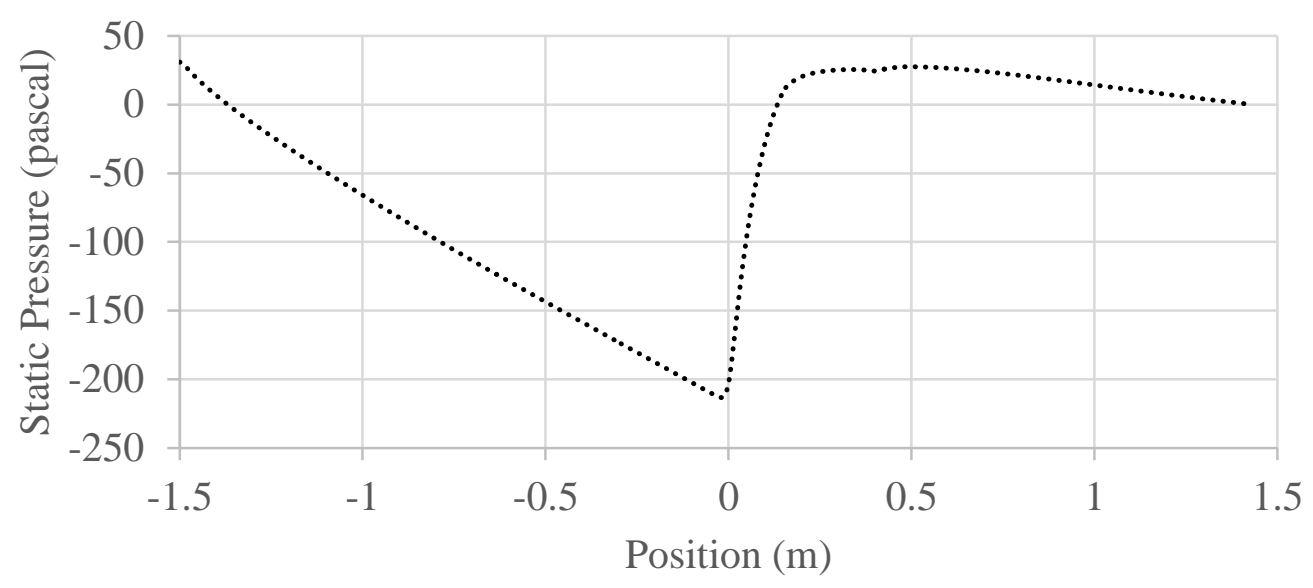

Figure 18. Plot of static pressure on the centre line of the tube

\section{CONCLUSION}

Computational fluid analysis on the S-shaped diffuser tube was carried out as part of a comprehensive computational analysis of the flow from the compressor, through the diffuser tube, the combustion chamber, and down to the turbine. Flow behaviour through the S-shaped diffuser tube was studied with the aims to evaluate the two turbulence models used. The numerical investigation was conducted using the ANSYSFluent, finite volume CFD solver along with Realizable $\kappa-\varepsilon$ and k- $\omega$ SST turbulence models. The results obtained showed that the Fluent k- $\omega$ SST model turned out to perform much better than the Realizable k- $\varepsilon$ turbulence model but still lack in shear stress modelling in near wall region. The Realizable $\mathrm{k}-\varepsilon$ turbulence model approximately failed to capture the qualitative and quantitative trend to predict the actual magnitudes of the calculated flow features. The Fluent k- $\omega$ SST also indicating a flattening of the stream wise velocity profile in the divergent part of diffuser and followed by a severe distortion, and a shift of the region of flow with the highest velocity toward the outer wall of the first bend. Flow separation does not take place over the diffuser tube range considerable pressure recovery potential. Low friction coefficients is a crucial technological feature in the investigation of flow passage. On the other hand, the pressure drops from $30.974 \mathrm{~Pa}$ at the inlet to $0.0254 \mathrm{~Pa}$ at the outlet.

\section{ACKNOWLEDGMENT}

The authors would like to thank University Teknologi Malaysia for financial supports of this research under GUP Grant no: Q.J130000.2624.11J92.

\section{REFERENCES}

[1] Heywood JB. Internal combustion engine fundamentals: Mcgraw-hill New York; 1988.

[2] Pulkrabek W. Engineering fundamentals of the internal combustion engine. Prentice Hall; 2004.

[3] Lumley JL. Engines: An introduction: Cambridge University Press; 1999.

[4] Dean W, Hurst J. Note on the motion of fluid in a curved pipe. Mathematika. 1959; 6(1): 77-85. 
[5] Berger SA, Talbot L, Yao LS. FLOW IN CURVED PIPES. Annual Review of Fluid Mechanics. 1983; 15: 461-512.

[6] Boersma BJ, Nieuwstadt FTM. Large-eddy simulation of turbulent flow in a curved pipe. Journal of Fluids Engineering, Transactions of the ASME. 1996; 118(2): 248-54.

[7] Dean WR. Note on the motion of fluid in a curved pipe. Philos Mag. 1927; 4(20): 208-23.

[8] Bovendeerd PHM, Van Steenhoven AA, Van De Vosse FN, Vossers G. Steady entry flow in a curved pipe. Journal of Fluid Mechanics. 1987; 177: 233-46.

[9] Ito H. FLOW IN CURVED PIPES. JSME International Journal. 1987; 30(262): 543-52.

[10] Goldsmith EL, Seddon J. Practical intake aerodynamic design: Amer Inst of Aeronautics; 1993.

[11] Vujičić MR, Crnojević C. Calculation of the turbulent flow in plane diffusers. International Journal of Numerical Methods for Heat \& Fluid Flow. 2007; 17(5): 533-47.

[12] Yang Y, Hou C. Numerical calculation of turbulent flow in symmetric twodimensional diffusers. Acta mechanica. 1999; 137(1): 43-54.

[13] Gerolymos GA, Joly S, Mallet M, Vallet I. Reynolds-Stress Model Flow Prediction in Aircraft-Engine Intake Double-S-Shaped Duct. Journal of Aircraft. 2010; 47(4): 1368-81.

[14] Lee GG, Allan WD, Boulama KG. Flow and performance characteristics of an Allison 250 gas turbine S-shaped diffuser: Effects of geometry variations. International Journal of Heat and Fluid Flow. 2013; 42: 151-63.

[15] Hüttl TJ, Friedrich R. Influence of curvature and torsion on turbulent flow in helically coiled pipes. International Journal of Heat and Fluid Flow. 2000; 21(3): 345-53.

[16] Giannakopoulos G, Frouzakis C, Boulouchos K, Fischer P, Tomboulides A. Direct numerical simulation of the flow in the intake pipe of an internal combustion engine. International Journal of Heat and Fluid Flow. 2017; 68: 25768.

[17] Di Piazza I, Ciofalo M. Numerical prediction of turbulent flow and heat transfer in helically coiled pipes. International Journal of Thermal Sciences. 2010; 49(4): 653-63.

[18] Lee G, Allan W, Boulama KG, editors. Numerical and experimental analysis of the airflow inside an A250 diffuser tube. Int Gas Turbine Institute Conf, Copenhagen, Denmark, Paper GT2012-69708; 2012.

[19] Menzies R. Computational Investigation of Flows in Diffusing S-shaped Intakes. Acta Polytechnica. 2001; 41(4-5).

[20] Gan W, Zhang X. Design optimization of a three-dimensional diffusing S-duct using a modified SST turbulent model. Aerospace Science and Technology. 2017; 63(Supplement C): 63-72.

[21] Lee J, Choi H, Ryu M, Cho J. A Study on Flow Characteristics of the Inlet Shape for the S-Duct. Journal of the Korean Society for Aeronautical \& Space Sciences. 2015; 43(2): 109-17.

[22] Kline SJ. Optimum design of straight-walled diffusers. Trans ASME Ser D J Basic Eng. 1954; 81: 321-31.

[23] Reneau LR, Johnston J, Kline SJ. Performance and design of straight, twodimensional diffusers. Journal of Basic Engineering. 1967; 89(1): 141-50. 
[24] Sagi C, Johnston J. The design and performance of two-dimensional, curved diffusers. ASME J Basic Eng. 1967; 89: 715-31.

[25] Sparrow EM, Abraham JP, Minkowycz WJ. Flow separation in a diverging conical duct: Effect of Reynolds number and divergence angle. International Journal of Heat and Mass Transfer. 2009; 52(13): 3079-83.

[26] Gibson A. On the flow of water through pipes and passages having converging or diverging boundaries. Proceedings of the Royal Society of London Series A, Containing Papers of a Mathematical and Physical Character. 1910; 83(563): 366-78.

[27] Pogorevc P, Kegl B. Optimal design of the intake system. University of Maribor, Faculty of Mechanical Engineering. 2007.

[28] Menter FR. Two-equation eddy-viscosity turbulence models for engineering applications. AIAA journal. 1994; 32(8): 1598-605.

[29] Fluent A. Fluent 14.0 User's Guide. ANSYS FLUENT Inc. 2011.

[30] Shih T-H, Liou WW, Shabbir A, Yang Z, Zhu J. A new k- $€$ eddy viscosity model for high reynolds number turbulent flows. Computers \& Fluids. 1995; 24(3): 227-38.

[31] Patankar SV, Spalding DB. A calculation procedure for heat, mass and momentum transfer in three-dimensional parabolic flows. International journal of heat and mass transfer. 1972;15(10):1787-806.

[32] Van Leer B. Towards the ultimate conservative difference scheme. Journal of Computational Physics. 1997;135(2):229-48.

[33] Peddiraju P, Papadopoulos A, Skaperdas V, Hedges L. Numerical simulations of flow through an S-duct. 6th BETA CAE International Conference 2015.

[34] Tu J, Yeoh GH, Liu C. Computational fluid dynamics: a practical approach: Butterworth-Heinemann; 2012.

[35] Marzouk OA, Huckaby ED. Simulation of a Swirling Gas-Particle Flow Using Different k-epsilon Models and Particle-Parcel Relationships. Engineering Letters. 2010;18(1).

[36] Lee K, Yu S. Computational studies of flows in the RAE 2129 S-shaped diffusing duct. AIAA Paper. 1994; 94: 0658. 